\title{
Karakteristik biopelet tempurung kelapa dan serbuk kayu sebagai bahan bakar alternatif
}

\author{
Muhammad Suyoko ${ }^{1}$, Kemas Ridhuan $^{2 *}$, Untung Surya Dharma ${ }^{3}$ \\ Jurusan Teknik Mesin, Fakultas Teknik, Universitas Muhammadiyah Metro ${ }^{1,2}$ \\ Prodi Teknik Mesin, Fakultas Teknik, Universitas Muhammadiyah Metro ${ }^{3,}$ \\ Jl. Ki Hajar Dewantara 15 A Kota Metro, Lampung, Indonesia \\ Coresponding author:muhammadsuyoko123@yahoo.com
}

\begin{abstract}
Biomass is a solid waste derived from biological material that can be generated as fuel. Biomass includes plantation, agriculture, household, forest waste and waste from the wood industry, one of the uses of biomass is bio-pellet. Bio-pellet is an alternative type of energy in the form of solid fuel made from biomass raw material with a size smaller than the size of briquettes. In this research, raw materials from teak wood, acacia, and sengon wood powder were used as well as a mixture of coconut shell charcoal with tapioca adhesive. This study aims to determine the bio-pellet estimation analysis, determine the heating value required by the bio pellet in the combustion process, and determine the burning characteristics of the three types of bio pellets. The method used in this study was the process of making bio-pellet with the same treatment on each bio-pellet, variations bio pellet will be made is 50\% teak wood powder and 50\% coconut shell charcoal powder, 50\% acacia wood powder and 50\% coconut shell charcoal powder, and 50\% sengon wood powder and 50\% coconut shell charcoal powder. Each bio pellet uses an adhesive mixture of $5 \%$ of the raw material. The stages of the testing process are bio pellet in laboratory tests to determine the value of the composition of the levels of heat, water, ash, flying substances, and bound carbon. The next testing process is the testing process of bio pellet combustion using a bio pellet stove with a process of boiling 10 liters of water, with fire temperature, water temperature, and the remaining fuel measured. All was done at UM Metro 2 campus. The results of bio pellet testing in the laboratory stated that the highest value was in sengon bio pellet with heating value of $5815.19 \mathrm{cal} / \mathrm{g}$, water content of $5.82 \%$, the ash content of $9.77 \%$, levels of flying matter $69.37 \%$, and carbon content bound 19, 41\%. For the high heating value of bio pellet burning is $784.92 \mathrm{kcal} / \mathrm{hour}$. Then the best efficiency is the sengon biopellet with a value of $55 \%$.
\end{abstract}

Keywords: Biomass, Fuel, Bio-pellet, Efficiency

\begin{abstract}
Abstrak
Biomassa adalah suatu limbah padat yang berasal dari material biologis yang bisa dimanfaatkan lagi sebagai bahan bakar. Biomassa meliputi limbah perkebunan, pertanian, rumah tangga, hutan serta limbah dari industri kayu, salah satu pemanfaatan biomassa adalah biopelet. Biopelet adalah jenis energi alternatif berupa bahan bakar padat yang berbahan baku biomassa dengan ukuran lebih kecil dari ukuran briket. dalam penelitian ini digunakan bahan baku dari serbuk kayu jati, akasia, dan sengon serta campuran arang tempurung kelapa dengan perekat tapioka. Tujuan penelitian ini adalah untuk mengetahui analisa proksimasi biopelet, mengetahui nilai kalor yang dibutuhkan biopelet dalam proses pembakaran, dan mengetahui karakteristik pembakaran dari tiga jenis biopelet tersebut.Metode yang dilakukan dalam penelitian ini adalah proses pembuatan biopelet dengan perlakuan sama pada tiap-tiap biopelet, variasi biopelet akan dibuat adalah 50\% serbuk kayu jati dan 50\% serbuk arang tempurung kelapa, 50\% serbuk kayu akasia dan 50\% serbuk arang tempurung kelapa, dan
\end{abstract}



50\% serbuk kayu sengon dan 50\% serbuk arang tempurung kelapa. Masing - masing biopelet menggunakan campuran perekat sebanyak 5\% dari bahan baku. Tahapan proses pengujiannya adalah biopelet di uji laboratorium guna mengetahui nilai komposisi kadar kalor, air, abu, zat terbang, dan karbon terikat. Proses pengujian selanjutnya adalah proses uji pembakaran biopelet dengan menggunakan kompor biopelet dengan proses pendidihan 10 liter air, dengan diukur suhu api, suhu air,dan sisa bahan bakar. Semua dilakukan dikampus 2 UM Metro. Hasil pengujian biopelet di laboratorium dinyatakan nilai yang tertinggi adalah pada biopelet sengon dengan kadar kalor 5815,19 kal/g, kadar air 5,82\%, kadar abu 9,77\%,kadar zat terbang $69,37 \%$, dan kadar karbon terikat $19,41 \%$. Untuk nilai kalor pembakaran biopelet yang tinggi adalah 784,92 kkal/jam. Kemudian efisiensi yang terbaik adalah pada biopelet sengon dengan nilai $55 \%$.

Kata Kunci : Biomassa, Bahan Bakar, Biopelet, Efisiensi

\section{Pendahuluan}

Kebutuhan minyak bumi saat ini sangat diperlukan untuk kepentingan masyarakat secara global, namun hal yang perlu diingat bahwasanya minyak bumi merupakan golongan sumber energi tidak terbarukan, karena dari hasil fosil zaman purba. Di sisi lain, produksi minyak nasional semakin lama semakin menurun. untuk mengatasi krisis energi yang terjadi diperlukan suatu usaha untuk mencari sumber - sumber energi alternatif baru yang lebih murah dan dapat diperbaharui. Salah satu bentuk energi alternatif adalah biomass Energy yang merupakan pemanfaatan bahan biologis sebagai sumber bahan bakar. Energi alternatif ini sangat cocok untuk dikembangkan di indonesia.

Indonesia memiliki potensi energi biomassa sebesar 50.000 Mega Watt yang bersumber dari berbagai biomassa limbah pertanian, seperti: produk plywood, penggilingan padi, pabrik gula, kakao, dan limbah pertanian lainya[1]. Hal ini merujuk pada melimpahnya sumber bahan bakar biomassa terutama di daerah provinsi lampung yang merupakan sebagian besar daerah penghasil kayu (bahan baku meubel).

Biomassa didefinisikan sebagi material tanaman, tumbuh - tumbuhan, atau sisa hasil pertanian yang digunakan sebagai bahan bakar atau sumber bahan bakar. Pemanfaatan limbah serbuk gergaji kayu sebagai bahan bakar rumah tangga atau industri - industri adalah biomass pellet (biopelet). Biopelet adalah jenis bahan bakar padat berbasis limbah dengan ukuran lebih kecil dari ukuran briket[2]. Biopelet dapat dibuat dari beberapa bahan biomassa seperti limbah serbuk kayu jati, serbuk kayu sengon, dan serbuk kayu akasia dengan campuran arang tempurung Kelapa. Biopelet adalah jenis energi alternatif berupa bahan bakar padat yang berbahan baku biomassa dengan ukuran lebih kecil dari ukuran briket. penggunaan bahan bakar biomassa secara langsung tanpa pengolahan akan menyebabkan timbulnya penyakit pernapasan yang disebabkan oleh karbon monoksida, sulfur dioksida $\left(\mathrm{SO}_{2}\right)$ dan bahan partikulat. Untuk dilakukan cara densifikasi dalam bentuk briket atau biopelet. Densifikasi adalah suatu metode pengembangan fungsi suatu sumberdaya. Densifikasi dapat meningkatkan kandungan energi tiap satuan volume dan juga dapat mengurangi biaya transportasi dan penanganan[3],

Pelet diproduksi oleh suatu alat dengan mekanisme pemasukan bahan secara terus - menerus serta mendorong bahan yang telah dikeringkan dan termampatkan melewati lingkaran baja dengan beberapa beberapa lubang yang memiliki ukuran tertentu. Proses pemampatan ini menghasilkan bahan yang padat dan akan patah ketika mencapai panjang yang diinginkan[4].

Penelitian ini dibuat biopelet dengan menggunakan variasi bahan baku 
biomassa limbah serbuk gergaji kayu jati, kayu akasia, kayu sengon dan campuran arang tempurung kelapa (diserbukan) dengan perekat tepung tapioka sebesar 5\%, sehingga diperoleh formulasi biopelet terbaik. proses pembentukan biopelet tanpa menghilangkan unsur kalori didalamnya akan mampu meningkatkan nilai kalor pembakaran biopelet yang dihasilkan.

Tujuan dari pada penelitian ini diuraikan sebagi berikut:

1. Mengetahui analisa proksimasi biopelet jati, akasia, dan sengon.

2. Mengetahui nilai kalor yang dibutuhkan oleh biopelet dalam proses pembakaran.

3. Mengetahui karakteristik pembakaran dengan berbagai bahan dari biomassa terhadap biopelet jati, akasia, dan sengon.

\section{Metode Penelitian}

Penelitian dilakukan di Laboratorium Teknik Mesin Universitas Muhammadiyah Metro dengan alokasi waktu dari bulan Januari sampai dengan Mei 2016. Metode pengambilan data adalah langkah dan prosedur yang akan dilakukan dalam pengumpulan data atau informasi. Dalam penelitian ini data atau informasi yang diperlukan dapat diperoleh melalui beberapa metode yaitu :

1. Studi Pustaka

Dalam metode ini penulis menggunakan buku, jurnal, tesis, serta internet yang ada hubungannya dengan biomassa biopelet dan pemanfaatannya serta dapat dipertanggung jawabkan kebenaranya sangat dibutuhkan untuk pengolahan data yang diperoleh dari lapangan.

2. Penelitian Lapangan (Observasi) Dalam metode ini penulis melakukan pengamatan secara langsung pada bahan baku biopelet dimana akan dilakukan penelitian serta mengambilan data yang kiranya dibutuhkan dalam penelitian.

3. Interview

Merupakan metode pengumpulan data dengan mengadakan secara langsung tanya jawab kepada orang-orang yang mengetahui biomassa biopelet serta orang - orang yang ahli dalam bidangnya.

4. Pengambilan data secara eksperimen yaitu bertujuan untuk melakukan pengambilan data secara langsung ke lokasi yang akan dilakukan penelitian guna mendapatkan data yang akurat, data ekperimen yang diambil meliputi bahan baku biopelet, perekatnya, dan data penunjang, seperti nilai kalor, kadar air, kadar abu, yang terkandung dalam biopelet, dan bahan perekat, serta dokumentasi lokasi. Bertujuan untuk mempermudah peneliti dalam menentukan pembuatan biopelet. Maka dalam hal ini data yang diperoleh dari hasil survey lokasi dan data tertulis akan diolah agar mendapatkan spesifikasi bahan baku, dan perekat yang digunakan dalam pembuatan biomassa biopelet.

\section{Hasil dan Pembahasan}

Biopelet yang dibuat dengan biomassa serbuk gergaji kayu jati, akasia, sengon dengan pencampuran arang tempurung kelapa dengan perekat tapioka. Variasi bahan bakar yang digunakan yaitu $50 \%$ serbuk kayu dan 50\% arang tempurung kelapa dan perekat $5 \%$ dari berat bahan baku. Dan biomassa serbuk kayu akasia, dan sengon dengan perlakuan sama. Pencetakan dalam 1 (satu) bentuk, yaitu silinder pejal. Hasil yang diperoleh seperti pada gambar berikut. 


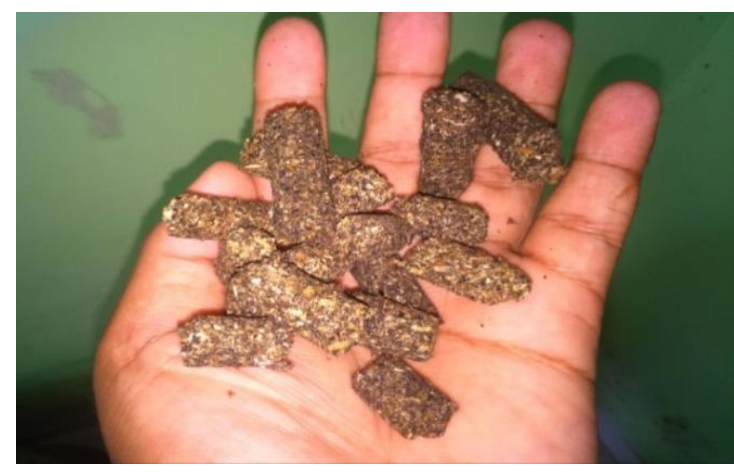

Gambar 1. Biopelet biomassa serbuk gergaji kayu dan arang tempurung kelapa dengan perekat tapioka.

Selama pengujian biopelet di laboratorium politeknik negeri lampung dengan mengetahui nilai kalor, kadar abu, kadar air, kadar karbon organik atau terikat, dan kadar zat terbang. Dari hasil analisa pengujian biopelet maka dapat diketahui berapa nilai - nilai dari kadar tersebut, sehingga dapat dibandingkan dengan Standar Nasional Indonesia (SNI) 8021:2014 dari Badan Standar Nasional (BSN).

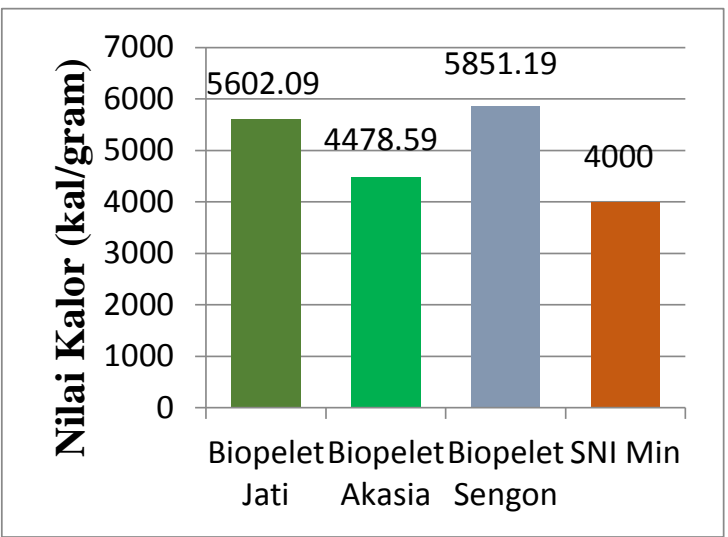

Gambar 2 Perbandingan nilai kalor biopelet jati, akasia dan sengon dengan kalor mutu SNI 8021:2014

Nilai kalor biopelet tertinggi terdapat pada perlakuan biopelet dengan campuran $50 \%$ serbuk kayu sengon dengan $50 \%$ serbuk arang tempurung kelapa dengan perekat tapioka sebesar $5851,19 \mathrm{kal} / \mathrm{gram}$. Nilai kalor terendah terdapat pada perlakuan biopelet dengan variasi $50 \%$ serbuk kayu akasia dengan $50 \%$ serbuk arang tempurung kelapa dengan perekat tapioka sebesar 4478,59 $\mathrm{kal} / \mathrm{gram}$. Hasil penelitian ini diperoleh hasil keseluruhan berkisar antara 4478,59 $\mathrm{kal} /$ gram sampai 5851,19 kal/gram, Keseluruhan dari biopelet jati, sengon, dan akasia telah memenuhi standar SNI 8021:2014 yang mensyaratkan minimum $4000 \mathrm{kal} / \mathrm{gram}$.

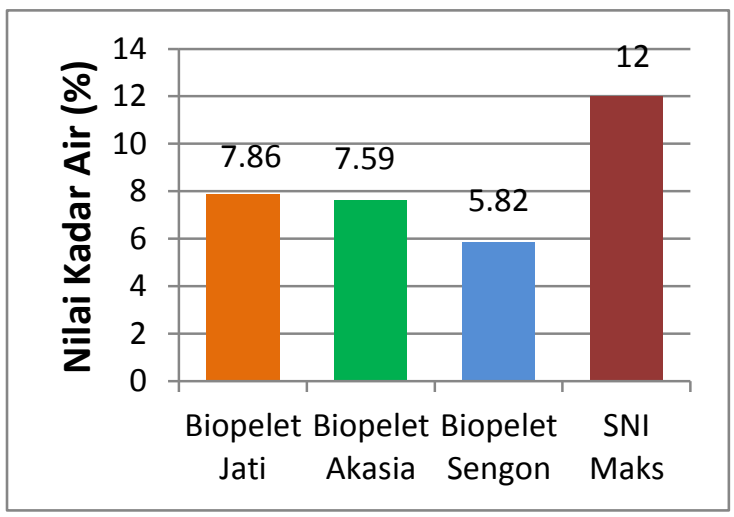

Gambar 3. Perbandingan nilai kadar air biopelet jati, akasia dan sengon dengan mutu SNI 8021:2014

Kadar air tertinggi terdapat pada perlakuan biopelet dengan campuran $50 \%$ serbuk kayu jati dengan 50\% serbuk arang tempurung kelapa dengan perekat tapioka sebesar 7,86 \%, nilai biopelet akasia sebesar $7,59 \%$ dengan perlakuan sama. Untuk nilai kadar air terendah pada perlakuan sama sebesar 5,82\%. Kadar air biopelet serbuk kayu jati, akasia, dan sengon pada penelitian ini telah memenuhi standar SNI 8021:2014 yang mensyaratkan maksimum $12 \%$ kadar air.

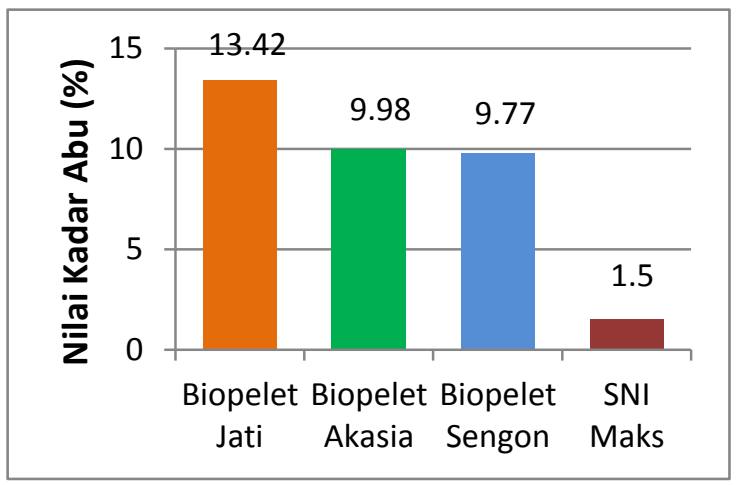


Gambar 4. Perbandingan nilai kadar abu biopelet jati, akasia dan sengon dengan mutu SNI 8021:2014

Kadar abu tertinggi sebesar 13,42\% terdapat pada perlakuan biopelet dengan campuran 50\% serbuk kayu jati dengan $50 \%$ serbuk arang tempurung kelapa dengan perekat tapioka, sedangkan kadar abu untuk biopelet akasia sebesar 9,98\%. Untuk kadar abu terendah pada biopelet sengon dengan perlakuan yang sama sebesar 9,77\%. Pada penelitian ini ketiga jenis bahan biopelet tidak memenuhi standar SNI 8021:2014 dengan kadar abu maksimum $1,5 \%$.

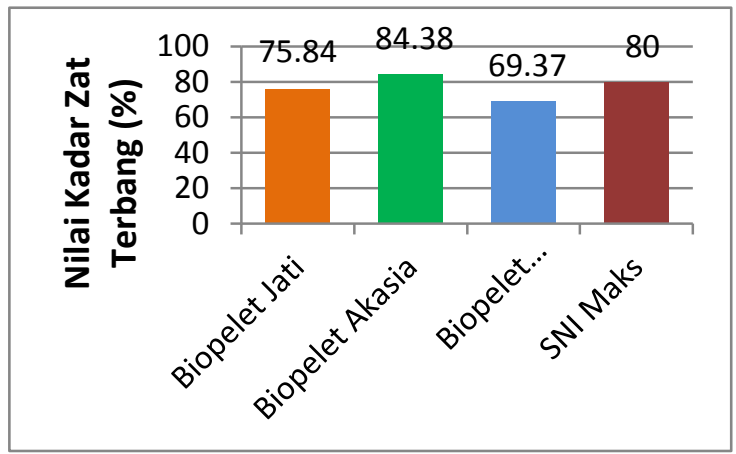

Gambar 5. Perbandingan nilai kadar zat terbang biopelet jati, akasia dan sengon dengan mutu SNI 8021:2014

Hasil penelitian kadar zat terbang tertinggi terdapat pada perlakuan biopelet akasia sebesar $84,38 \%$, kemudian pada biopelet jati sebesar $75,84 \%$. Untuk kadar zat terbang terendah biopelet sengon yaitu sebesar 69,37\%. Pada penelitian ini biopelet jati dan sengon telah memenuhi standar SNI, sedangkan biopelet akasia melebihi batas maksimal SNI 8021:2014 yang mensyaratkan nilai maksimum kadar zat terbang sebesar $80 \%$.

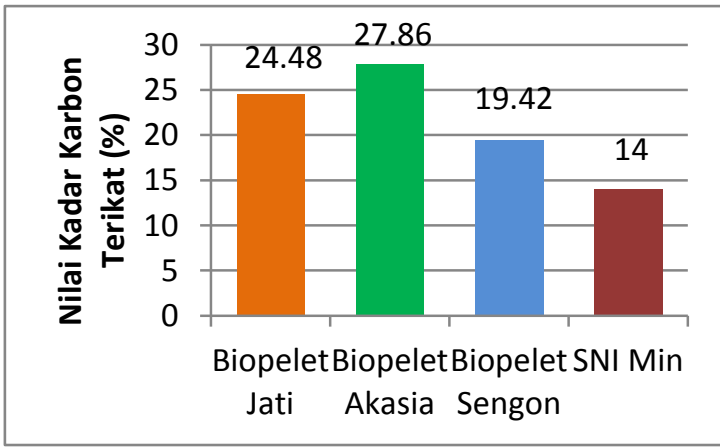

Gambar 6. Perbandingan nilai kadar karbon organik/terikat biopelet jati, akasia dan sengon dengan mutu SNI 8021:2014

Hasil penelitian menunjukan kadar karbon terikat tertinggi terdapat pada biopelet akasia sebesar $27,86 \%$, sedangkan pada biopelet jati sebesar $24,48 \%$. Untuk kadar karbon terikat biopelet terendah terdapat pada biopelet sengon sebesar 19,42\%. Berdasarkan hasil penelitian pada biopelet akasia memiliki nilai karbon terikat tinggi. Ketiga sampel biopelet yaitu biopelet jati, akasia, dan sengon telah memenuhi standar SNI 8021:2014 yang mensyaratkan nilai minimum $14 \%$.

\section{Hasil Pengujian Pembakaran Biopelet Pada Kompor Biopelet}

Metode yang digunakan untuk pengujian pembakaran keseluruhan untuk pembakaran biopelet pada kompor biomassa yaitu pengujian pendidihan air.

Tabel 1. Data Analisa pengujian pembakaran $1 \mathrm{~kg}$ biopelet jati terhadap pendidihan 10 liter air.

\begin{tabular}{|c|c|c|c|}
\hline \multirow{2}{*}{$\begin{array}{c}\text { Lama } \\
\text { pembakaran } \\
\text { (menit) }\end{array}$} & \multicolumn{2}{|c|}{ Temperatur } & \multirow{2}{*}{ Keterangan } \\
\hline & $\begin{array}{l}\text { Air } \\
\left({ }^{\circ} \mathrm{C}\right)\end{array}$ & $\begin{array}{l}\text { Api } \\
\left({ }^{\circ} \mathrm{C}\right)\end{array}$ & \\
\hline 0 & 30 & 250 & \multirow{14}{*}{$\begin{array}{l}\text {-Temperatur maks. Air } \\
\left(\mathrm{T}_{2}\right)=70^{\circ} \mathrm{C} \\
\text {-Temperatur maks. Api } \\
=508^{\circ} \mathrm{C} \text {. } \\
*=\text { puncak suhu api } \\
\text { tertinggi } \\
* *=\text { penurunan suhu api }\end{array}$} \\
\hline 2 & 34 & 381 & \\
\hline 4 & 37 & 387 & \\
\hline 6 & 39 & 390 & \\
\hline 8 & 41 & 396 & \\
\hline 10 & 43 & 399 & \\
\hline 12 & 45 & 410 & \\
\hline 14 & 48 & 415 & \\
\hline 16 & 50 & 420 & \\
\hline 18 & 54 & 430 & \\
\hline 20 & 58 & 452 & \\
\hline 22 & 61 & 462 & \\
\hline 24 & 63 & 473 & \\
\hline 26 & 65 & 485 & \\
\hline
\end{tabular}




\begin{tabular}{|c|c|c|}
\hline 28 & 67 & 494 \\
\hline 30 & 70 & $508 *$ \\
\hline 32 & 70 & $473 * *$ \\
\hline 34 & 68 & $451 * *$ \\
\hline 36 & 67 & $438 * *$ \\
\hline 38 & 65 & $381 * *$ \\
\hline 40 & 64 & $327 * *$ \\
\hline 42 & 64 & $292 * *$ \\
\hline
\end{tabular}

Dari data tabel 1 kalor yang dibutuhkan dalam pendidihan air, dapat dihitung dengan rumus:

$Q n 1=\frac{m f \cdot c \cdot \Delta T}{t}$

$=\frac{10 \mathrm{~kg} \times 0,999 \mathrm{kcal} / \mathrm{kg} \times\left(70^{\circ} \mathrm{C}-30^{\circ} \mathrm{C}\right)}{0,7 \mathrm{jam}}$

$=\frac{9,99 \mathrm{kcal} \times 40^{\circ} \mathrm{C}}{0,7 \mathrm{jam}}$

$=570,857 \mathrm{Kcal} / \mathrm{jam}$

Energi yang diserap oleh air adalah sebesar $570,857 \mathrm{Kkal} / \mathrm{jam}$, pada proses pendidihan air $10 \mathrm{~kg}$. Pada tabel diatas menunjukan bahwa durasi awal waktu pembakaran sampai api padam, awal pembakaran api bersuhu $250^{\circ} \mathrm{C}$ dengan suhu air awal $30^{\circ} \mathrm{C}$, kemudian mengalami kenaikan suhu tertinggi pada api sebesar $508^{\circ} \mathrm{C}$ dan suhu air meningkat sampai $70^{\circ} \mathrm{C}$ pada menit 30 , setelah itu suhu api mengalami penurunan sampai api padam padam menit ke 42 , yang berdampak terhadap menurunnya suhu air sebesar $64^{\circ} \mathrm{C}$ pada menit ke 42 . Hal ini terjadi pada proses pembakaran bahan bakar biopelet kayu jati pada proses pengujian dengan cara mendidihkan air 10 liter.

Tabel 2. Data Analisa pengujian pembakaran $1 \mathrm{~kg}$ biopelet akasia terhadap pendidihan 10 liter air.

\begin{tabular}{|c|c|c|c|}
\hline \multirow{2}{*}{$\begin{array}{c}\text { Lama } \\
\text { pembakaran } \\
\text { (menit) }\end{array}$} & \multicolumn{2}{|c|}{ Temperatur } & \multirow{2}{*}{ Keterangan } \\
\hline & $\begin{array}{l}\text { Air } \\
\left({ }^{\circ} \mathrm{C}\right)\end{array}$ & $\begin{array}{l}\text { Api } \\
\left({ }^{\circ} \mathrm{C}\right)\end{array}$ & \\
\hline
\end{tabular}

\begin{tabular}{|c|c|c|c|}
\hline 0 & 30 & 234 & \multirow{20}{*}{$\begin{array}{l}\text {-Temperatur maks. Air }\left(\mathrm{T}_{2}\right) \\
=65^{\circ} \mathrm{C} \\
\text { - Temperatur maks. Api }(= \\
448^{\circ} \mathrm{C} \text {. } \\
*=\text { puncak suhu api } \\
\text { tertinggi } \\
* *=\text { penurunan suhu api }\end{array}$} \\
\hline 2 & 35 & 376 & \\
\hline 4 & 37 & 386 & \\
\hline 6 & 39 & 391 & \\
\hline 8 & 41 & 394 & \\
\hline 10 & 43 & 396 & \\
\hline 12 & 45 & 399 & \\
\hline 14 & 48 & 406 & \\
\hline 16 & 51 & 415 & \\
\hline 18 & 54 & 423 & \\
\hline 20 & 56 & 430 & \\
\hline 22 & 59 & 441 & \\
\hline 24 & 62 & 445 & \\
\hline 26 & 65 & $448^{*}$ & \\
\hline 28 & 64 & $441^{* *}$ & \\
\hline 30 & 63 & $398^{* *}$ & \\
\hline 32 & 61 & $328^{* *}$ & \\
\hline 34 & 60 & $289^{* *}$ & \\
\hline 36 & 59 & $270^{* *}$ & \\
\hline 38 & 58 & $250^{* *}$ & \\
\hline
\end{tabular}

Dari data tabel 2 analisa kalor yang dibutuhkan dalam pendidihan air, dapat dihitung dengan rumus:

$Q n 2=\frac{m f \cdot c \cdot \Delta T}{t}$

$=\frac{10 \mathrm{~kg} \times 0,999 \mathrm{kcal} / \mathrm{kg} \times\left(65^{\circ} \mathrm{C}-30^{\circ} \mathrm{C}\right)}{0,63 \mathrm{jam}}$

$=\frac{9,99 \mathrm{kcal} \times 35^{\circ} \mathrm{C}}{0,63 \mathrm{jam}}$

$=555 \mathrm{Kcal} / \mathrm{jam}$

Dilihat pada tabel 2 suhu awal api nyala sebesar $234^{\circ} \mathrm{C}$ pada menit pertama dan suhu air $30^{\circ} \mathrm{C}$, mengalami kenaikan suhu api dan air pada menit ke 26 yaitu suhu api $448^{\circ} \mathrm{C}$ dan suhu air mencapai $65^{\circ} \mathrm{C}$. Mengalami penurunan suhu api dan air pada menit ke 27 sampai 38 yang dinyatakan api padam.

Tabel 3. Data Analisa pengujian pembakaran $1 \mathrm{~kg}$ biopelet Sengon terhadap pendidihan 10 liter air. 


\begin{tabular}{|c|c|c|c|}
\hline \multirow{2}{*}{$\begin{array}{c}\text { Lama } \\
\text { pembakaran } \\
\text { (menit) }\end{array}$} & \multicolumn{2}{|c|}{ Temperatur } & \multirow[t]{2}{*}{ Keterangan } \\
\hline & $\begin{array}{l}\text { Air } \\
\left({ }^{\circ} \mathrm{C}\right)\end{array}$ & $\begin{array}{l}\text { Api } \\
\left({ }^{\circ} \mathrm{C}\right)\end{array}$ & \\
\hline 0 & 30 & 300 & \multirow{18}{*}{$\begin{array}{l}\text {-Temperatur maks. Air } \\
\left(\mathrm{T}_{2}\right)=74^{\circ} \mathrm{C} \\
\text { - Temperatur maks. Api }( \\
=583^{\circ} \mathrm{C} . \\
*=\text { puncak suhu api } \\
\text { tertinggi } \\
* *=\text { penurunan suhu api }\end{array}$} \\
\hline 2 & 38 & 380 & \\
\hline 4 & 42 & 395 & \\
\hline 6 & 44 & 406 & \\
\hline 8 & 46 & 410 & \\
\hline 10 & 48 & 420 & \\
\hline 12 & 50 & 430 & \\
\hline 14 & 53 & 546 & \\
\hline 16 & 65 & 563 & \\
\hline 18 & 69 & 572 & \\
\hline 20 & 71 & 575 & \\
\hline 22 & 73 & 580 & \\
\hline 24 & 74 & $583 *$ & \\
\hline 26 & 73 & $503^{* * *}$ & \\
\hline 28 & 72 & $403^{* * *}$ & \\
\hline 30 & 71 & $300^{* * *}$ & \\
\hline 32 & 69 & $250^{* * *}$ & \\
\hline 34 & 68 & $238^{* * *}$ & \\
\hline
\end{tabular}

Dari data tabel 3 analisa kalor yang dibutuhkan dalam pendidihan air, dapat dihitung dengan rumus:

$Q n 3=\frac{m f \cdot c \cdot \Delta T}{t}$

$=\frac{10 \mathrm{~kg} \times 0,999 \mathrm{kcal} / \mathrm{kg} \times\left(74^{\circ} \mathrm{C}-30^{\circ} \mathrm{C}\right)}{0,56 \mathrm{jam}}$

$=\frac{9,99 \mathrm{kcal} \times 44^{\circ} \mathrm{C}}{0,56 \mathrm{jam}}$

$=784,92 \mathrm{Kcal} / \mathrm{jam}$

Energi yang diserap oleh air adalah sebesar $784,92 \mathrm{Kkal} / \mathrm{jam}$, pada proses pendidihan air $10 \mathrm{~kg}$. Pada tabel 3. awal pembakaran suhu api sebesar $300^{\circ} \mathrm{C}$ dengan suhu awal air $30^{\circ} \mathrm{C}$, mengalami kenaikan tertinggi pada suhu api sebesar $583^{\circ} \mathrm{C}$ dan suhu air $74^{\circ} \mathrm{C}$ pada menit ke 24 . Dan mengalami penurunan suhu api dan air dimulai dari menit ke 25 sampai api padam pada menit ke 34 .

\section{Pengujian Bahan Bakar Biopelet Terhadap Laju Pembakaran Biopelet.}

Laju bahan bakar biopelet adalah kecepatan bahan bakar habis sampai menjadi arang dengan berat tertentu. Adapun data hasil pengujian diantaranya:

Tabel 4. Data Analisa pengujian pembakaran biopelet.

\begin{tabular}{|l|l|l|l|l|l|}
\hline \multirow{2}{*}{ No } & $\begin{array}{l}\text { Jenis } \\
\text { Biopelet }\end{array}$ & \multicolumn{3}{|l|}{$\begin{array}{l}\text { Massa Bahan Bakar } \\
(\mathrm{kg})\end{array}$} & $\begin{array}{l}\text { Waktu } \\
\text { (Menit) }\end{array}$ \\
\cline { 3 - 5 } & & $\mathrm{Bb} 0$ & $\mathrm{Bb} 1$ & $\mathrm{Bb} 2$ & \\
\hline 1 & Jati & 1 & 0,170 & 0,830 & 42 \\
\hline 2 & Akasia & 1 & 0,200 & 0,800 & 38 \\
\hline 3 & Sengon & 1 & 0,130 & 0,870 & 34 \\
\hline
\end{tabular}

Ket.

$\mathrm{Bb} 0=$ bahan bakar awal

Bb1 = bahan bakar akhir

$\mathrm{Bb} 2=$ bahan bakar terpakai

$F C R=$ laju Konsumsi biopelet $(\mathrm{kg} / \mathrm{jam})$

Dari data Pengujian Pembakaran biopelet, untuk mengetahui laju pembakaran bahan bakar dapat dihitung dengan cara:

1. Laju Konsumsi Bahan bakar Biopelet Jati

$$
\begin{aligned}
& F C R I=\frac{B b 1}{T} \\
& =\frac{0,170 \mathrm{~kg}}{0,7 \mathrm{jam}} \\
& =0,24 \mathrm{~kg} / \mathrm{jam}
\end{aligned}
$$

2. Laju Konsumsi Bahan bakar Biopelet Akasia

$$
\begin{aligned}
& F C R 2=\frac{B b 1}{T} \\
& =\frac{0,200 \mathrm{~kg}}{0,63 \mathrm{jam}} \\
& =0,31 \mathrm{~kg} / \mathrm{jam}
\end{aligned}
$$

3. Laju Konsumsi Bahan bakar Biopelet Sengon 


$$
\begin{aligned}
& F C R 3=\frac{B b 1}{T} \\
& =\frac{0,130 \mathrm{~kg}}{0,56 \mathrm{jam}} \\
& =0,23 \mathrm{~kg} / \mathrm{jam}
\end{aligned}
$$

\section{Perhitungan Efisiensi Pembakaran Biopelet}

Untuk mengetahui efisiensi pembakaran biopelet dapat dihitung dengan rumus:

Diketahui:

Nilai kalor bahan bakar (HVF) biopelet jati $=5602,09 \mathrm{kkal} / \mathrm{kg}$. Nilai kalor bahan bakar $(\mathrm{HVF})$ biopelet akasia $=4478,59 \mathrm{kkal} / \mathrm{kg}$. Nilai kalor bahan bakar (HVF) biopelet sengon $=5851,19 \mathrm{kkal} / \mathrm{kg}$

A. Efisiensi pembakaran biopelet jati

$$
\begin{aligned}
& \eta 1=\frac{Q n 1}{F C R 1 \times H V F} \times 100 \% \\
& =\frac{570,857 \frac{\mathrm{Kkal}}{\mathrm{jam}}}{0,24 \frac{\mathrm{kg}}{\mathrm{jam}} \times 5602,09 \frac{\mathrm{kkal}}{\mathrm{kg}}} \times 100 \% \\
& =41 \%
\end{aligned}
$$

B. Efisiensi Pembakaran Biopelet Akasia

$$
\begin{aligned}
& \eta^{2}=\frac{Q n 2}{F C R 2 \times H V F} \times 100 \% \\
& =\frac{555 \frac{\mathrm{Kkal}}{\mathrm{jam}}}{0,31 \frac{\mathrm{kg}}{\mathrm{jam}} \times 4478,59 \frac{\mathrm{kkal}}{\mathrm{kg}}} \times 100 \% \\
& =39 \%
\end{aligned}
$$

C. Efisiensi Pembakaran Biopelet Sengon

$$
\eta 3=\frac{Q n 3}{F C R 3 \times H V F} \times 100 \%
$$

$$
\begin{aligned}
& =\frac{784,42 \frac{\mathrm{Kkal}}{\mathrm{jam}}}{0,24 \frac{\mathrm{kg}}{\mathrm{jam}} \times 5851,19 \frac{\mathrm{kcal}}{\mathrm{kg}}} \times 100 \% \\
& =55 \%
\end{aligned}
$$

\section{Kesimpulan}

Berdasarkan dari hasil penelitian yang telah dilakukan maka dapat di ambil kesimpulan sebagai berikut:

1. Hasil uji laboratorium biopelet.

\begin{tabular}{|l|l|l|l|l|l|}
\hline \multirow{2}{*}{$\begin{array}{l}\text { Bio } \\
\text { pelet }\end{array}$} & \multicolumn{5}{|l|}{ Nilai Proksimasi Biopelet } \\
\cline { 2 - 6 } & Kadar & Kadar & Kadar \\
& abu & $\begin{array}{l}\text { Kat } \\
(\%)\end{array}$ & $\begin{array}{l}\text { Kadar } \\
\text { Terbang } \\
(\%)\end{array}$ & $\begin{array}{l}\text { Kadar } \\
\text { Terikat } \\
(\%)\end{array}$ & $\begin{array}{l}\text { Kalor } \\
(\mathrm{Kal} / \mathrm{g})\end{array}$ \\
\hline Jati & 7,86 & 13,42 & 75,84 & 24,48 & 5602,09 \\
\hline Akasia & 7,59 & 9,98 & 84,38 & 27,86 & 4474,59 \\
\hline Sengon & 5,82 & 9,77 & 69,37 & 19,42 & 5815,19 \\
\hline
\end{tabular}

2. Hasil uji pembakaran biopelet dengan mendidihkan air 10 liter yaitu nilai kalor yang dibutuhkan biopelet jati sebesar 570,857 $\mathrm{kkal} / \mathrm{jam}$, untuk nilai kalor biopelet akasia sebesar $555 \mathrm{kkal} / \mathrm{jam}$, dan nilai kalor biopelet sengon sebesar 784,92 kkal/jam.

3. Karakteristik Pada biopelet jati nilai FCR sebesar 0,24, lama waktu pembakaran sebesar 42 menit, suhu api tertinggi sebesar $508{ }^{\circ} \mathrm{C}$, dan Efisiensi $41 \%$. Pada biopelet akasia FCR sebesar 0,31, lama waktu pembakaran sebesar 38 menit, suhu api tertinggi sebesar $448{ }^{\circ} \mathrm{C}$, dan Efisiensi 39\%. Pada biopelet sengon FCR sebesar 0,23, lama waktu pembakaran sebesar 34 menit, suhu 
4. api tertinggi sebesar $583{ }^{\circ} \mathrm{C}$, dan Efisiensi 55\%.

\section{Referensi}

[1]. Prihandana R, Handoko R. 2007. Energi Hijau. Jakarta. Penerbit Swadaya. Saptoadi H. 2006.

The Best Biobriquentte Dimension and The $2^{\text {nd }}$ Joint International conference on "Sustainable energy and Environment (SEE 2006)" 21 23 November 2006, Bangkok. Thailand.

[2]. Windarwati S. 2011. Seminar Nasional Teknologi Kimia. Bogor.

[3]. Saptoadi H. 2006.The Best Biobriquette Dimension and its Particle Size. The $2^{\text {nd }}$ Joint International Conference on "Sustainable Energy and Environment (SEE 2006) "2123 November 2006. Bangkok

[4]. Zamira F. 2009. Pembuatan Biopelet dari Bungkil Jarak Pagar (Jathropa curcas L) dengan Penambahan Sludge dan Perekat Tapioka. (Skripsi): Fakultas Teknologi IPB. Bogor. 